\title{
HUBUNGAN ANTARA JENIS TERAPI HIPERTENSI PADA ANGKA KEJADIAN GAGAL GINJAL DI RSUD DR. R. SOEDJONO SELONG
}

\author{
Muhammad Nauval*, Uswatun Hasanah** \\ Fakultas Kedokteran Universitas Islam Al-Azhar \\ J1. Unizar No.20 Turida Mataram
}

\begin{abstract}
ABSTRAK
Hipertensi merupakan penyebab utama terjadinya end-stage renal disease (ERDS) bersama dengan diabetes mellitus. Hipertensi yang berlangsung lama dapat mengakibatkan perubahanperubahan struktur pada arteriol di seluruh tubuh, ditandai dengan fibrosis dan sklerosis dinding pembuluh darah. Organ sasaran utama keadaan ini adalah salah satunya ginjal. Beratnya pengaruh hipertensi pada ginjal tergantung dari tingginya tekanan darah dan lamanya menderita hipertensi. Semakin tinggi tekanan darah dalam waktu lama maka semakin berat komplikasi yang dapat ditimbulkan. Pemberian terapi hipertensi yang adekuat akan dapat mencegah komplikasi yang di timbulkan oleh penyakit hipertensi. Terapi kombinasi diberikan untuk meningkatkan kontrol tekanan darah dalam batas normal pada penderita hipertensi.

Subjek penelitian merupakan pasien hipertensi kronis dengan lama hipertensi > 3 tahun. Jumlah sample dalam penelitian ini adalah 79 orang. Pengambilan data dilakukan dengan penelusuran rekam medis pasien hipertensi kronis yang berobat di RSUD DR. R Soedjono selong. Subjek pria sebanyak 35 orang $(44,3 \%)$ dan wanita 44 orang $(55,7 \%)$. Sebanyak $34(43,03 \%)$ orang mendapatkan monoterapi, dan $45(56,96 \%)$ orang lainnya menerima terapi kombinasi.

Jenis penelitian ini adalah observasional analitik dengan pendekatan rancangan Cross sectional. Tempat penelitian dilaksanakan di Rumah Sakit Umum Daerah Dr. R. Soedjono Selong. Waktu penelitian dilaksanakan pada bulan April-Mei 2017.

Hasil Uji Chi Kuadrat $\left(\mathrm{X}^{2}\right)$ diperoleh nilai signifikan 0,001 ( $\left.\mathrm{p}<0,05\right)$ dan CI 95\% 1.1061.303, berarti terdapat hubungan bermakna antara jenis terapi hipertensi dengan kejadian gagal ginjal pada RSUD DR. R. Soedjono Selong. Odds Ratio (OR) di dapatkan sebesar 5.147. (CI 95\% : 1.960-13.513) menunjukkan terdapat hubungan yang bermakna antara jenis terapi hipertensi dengan kejadian gagal ginjal.
\end{abstract}

Kata Kunci : Hipertensi, terapi kombinasi, gagal ginjal

\section{PENDAHULUAN}

Gagal ginjal kronis merupakan gangguan fungsi renal kronik progresif ireversibel dimana kemampuan tubuh tidak mampu untuk mempertahankan keseimbangan cairan, metabolisme, dan elektrolit (Mansjoer dkk, 2004). Berdasarkan data di United States Renal Data System, gagal ginjal kronis meningkat sebesar $20-25 \%$ setiap tahunnya (USRD, 2006). Ginjal dan hipertensi berkaitan dengan erat, hipertensi dapat menimbulkan kerusakan ginjal dan kerusakan ginjal dapat menyebabkan hipertensi (Roesma, 2008).
Hipertensi yang berlangsung lama dapat mengakibatkan perubahan-perubahan struktur pada arteriol di seluruh tubuh, ditandai dengan fibrosis dan sklerosis dinding pembuluh darah. Organ sasaran utama keadaan ini adalah salah satunya ginjal (Price \& Wilson, 2013).

Pada tahun 2001, WHO melaporkan penelitian di Bangladesh dan India dengan hasil prevalensi terjadinya hipertensi $65 \%$ dari jumlah penduduknya, dengan prevalensi tertinggi pada penduduk di daerah perkotaan. Menurut laporan pertemuan WHO di Jenewa tahun 2002 didapatkan prevalensi penyakit 
hipertensi $15-37 \%$ dari populasi penduduk dewasa di dunia. Di Asia, tercatat 38,4 juta penderita hipertensi pada tahun 2000 dan diprediksi akan meningkat menjadi 67,4 juta orang pada tahun 2025 (Kementerian Kesehatan Republik Indonesia, 2013).

Prevalensi hipertensi di Indonesia yang didapat melalui pengukuran tekanan darah pada umur $\geq 18$ tahun sebesar 25,8 persen, tertinggi di Bangka Belitug (30,9\%), diikuti Kalimantan Selatan (30,8\%), Kalimantan Timur (29,6\%), dan Jawa Barat (29,4\%). Di NTB, prevalensi hipertensi berdasarkan hasil pengukuran tekanan darah adalah 37,8\% (nasional $25,8 \%$ ), sementara berdasarkan diagnosis dan atau riwayat minum obat hipertensi prevalensinya adalah 6,7\% (Riskesdas, 2013).

Berdasarkan penyebabnya
hipertensi dibedakan menjadi dua
golongan yaitu hipertensi primer dan
hipertensi sekunder. Hipertensi primer
atau hipertensi esensial terjadi karena
peningkatan persisten tekanan arteri
akibat ketidakteraturan mekanisme
kontrol homeostatik normal, dapat juga
disebut hipertensi idiopatik. Hipertensi ini
mencakup sekitar 95\% kasus.
Hipertensi sekunder atau hipertensi
renal merupakan hipertensi yang
penyebabnya diketahui dan terjadi sekitar
10\% dari kasus-kasus hipertensi. Hampir
semua hipertensi sekunder berhubungan

dengan ganggaun sekresi hormon dan fungsi ginjal. (Sudoyo dkk, 2009).

Beratnya pengaruh hipertensi pada ginjal tergantung dari tingginya tekanan darah dan lamanya menderita hipertensi. Semakin tinggi tekanan darah dalam waktu lama maka semakin berat komplikasi yang dapat ditimbulkan (Sudoyo dkk, 2009).

Hipertensi merupakan pemicu terjadinya penyakit ginjal dan juga faktor pengembang. Pasien dengan penyakit ginjal tahap akhir biasanya memiliki komplikasi hipertensi, sebanyak 50-60\% pasien mengalami hipertensi dengan tekanan darah predialisis $>150 / 90 \mathrm{mmHg}$. Target kontrol tekanan darah pada pasien penyakit ginjal tahap akhir yang menjalani dialisis menurut NKF-KDOQI guidelines (2005) pada predialisis harus $<140 / 90 \mathrm{mmHg}$ dan untuk postdialisisnya adalah $<130 / 80 \mathrm{mmHg}$.

Pemberian terapi hipertensi yang adekuat akan dapat mencegah komplikasi yang di timbulkan oleh penyakit hipertensi. Terapi kombinasi diberikan untuk meningkatkan kontrol tekanan darah dalam batas normal pada penderita hipertensi. Penderita hipertensi kronis $>5$ tahun beresiko menderita gagal ginjal hingga 4x lipat (hidayati, 2008)

Berdasarkan data di atas peneliti tertarik melakukan penelitian mengenai hubungan a ntara jenis terapi hipertensi dengan kejadian gagal ginjal di RSUD 
R. Soedjono Selong.

\section{METODE}

Jenis penelitian ini adalah observasional analitik dengan pendekatan rancangan Cross sectional. Tempat penelitian dilaksanakan di Rumah Sakit Umum Daerah Dr. R. Soedjono Selong. Waktu penelitian dilaksanakan pada bulan April-Mei 2017.

Subjek penelitian merupakan pasien hipertensi kronis dengan lama hipertensi > 3 tahun. Jumlah sample dalam penelitian ini adalah 79 orang. Pengambilan data dilakukan dengan penelusuran rekam medis pasien hipertensi kronis yang berobat di RSUD DR. R Soedjono selong. Data yang di kumpulkan adalah jenis terapi yang di berikan (monoterapi atau kombinasi terapi) dan diagnosis gagal ginjal pasien.

Analisis deskriptif dilakukan untuk menilai karakteristik umum pasien hipertensi kronis. Sedangkan analisa statistik menggunakan metode chi square untuk menilai hubungan dan Prevalence risk antara jenis terapi dan gagal ginjal kronis.

\section{HASIL DAN PEMBAHASAN}

Subjek pada penelitrian ini sebanyak 79 orang dengan hipertensi kronis. Subjek pria sebanyak 35 orang $(44,3 \%)$ dan wanita 44 orang $(55,7 \%)$.

Dengan karakteristik sesuai usia sebagai berikut :

Tabel 1.1. Karakteristik usia pasien

\begin{tabular}{|c|c|c|c|}
\hline Usia & Jumlah & Persentase & Total \\
\cline { 1 - 3 } $\begin{array}{c}25-44 \\
\text { Tahun }\end{array}$ & 16 & $20.3 \%$ & \\
\cline { 1 - 2 } $\begin{array}{c}45-65 \\
\text { Tahun }\end{array}$ & 53 & $67.0 \%$ & \multirow{2}{*}{79} \\
\cline { 1 - 2 } $\begin{array}{c}>65 \\
\text { Tahun }\end{array}$ & 10 & $12.7 \%$ & \\
\hline
\end{tabular}

Sebanyak $34 \quad(43,03 \%) \quad$ orang mendapatkan monoterapi, dan 45 $(56,96 \%)$ orang lainnya menerima terapi kombinasi. Berikut jenis obat yang digunakan untuk mengontrol tekanan darah pasien :

Tabel 2.1. Karakteristik terapi yang digunakan pasien

\begin{tabular}{|c|c|c|c|}
\hline \multicolumn{2}{|c|}{ Monoterapi } & \multicolumn{2}{c|}{$\begin{array}{c}\text { Kombinasi } \\
\text { terapi }\end{array}$} \\
\hline Amlodipine & 22 & $\begin{array}{c}\text { Amlodipine } \\
\text { + valsartan }\end{array}$ & 33 \\
\hline Valsartan & 9 & $\begin{array}{c}\text { Captopril + } \\
\text { valsartan }\end{array}$ & 2 \\
\hline Captopril & 3 & $\begin{array}{c}\text { Amlodipine } \\
\text { +captopril }\end{array}$ & 8 \\
\hline & & $\begin{array}{c}\text { Nicardipine } \\
\text { + valsrtan+ }\end{array}$ & 2 \\
\hline Total & 34 & & 45 \\
\hline
\end{tabular}

Hasil analsis statistik menggunakan chi square didapatkan bahwa sebanyak 36 orang subjek yang tidak mengalami gagal ginjal kronis yang terdiri dari 23 (29.1\%) pasien yang mendapatkan mono terapi dan $13(16.5 \%)$ pasien dengan terapi kombinasi. Sedangkan di dapatkan 43 pasien dengan gagal ginjal.

Berdasarkan hasil uji statistik bivariat yang dilakukan dengan metode 
chisquare di temukan Relative Risk (RR)/ rasio prevalensi sebesar $2,9 \mathrm{x}$ terjadinya hipertensi pada pasien yang mendapatkan terapi kombinasi dengan nilai p 0,001 $(\mathrm{p}<0,005)$ yang berarti bahwa variabel independen adalah faktor resiko yang mempengaruhi variabel dependen, yang dalam hal ini bahwa jenis terapi hipertensi kemungkinan merupakan faktor risiko untuk timbulnya penyakit gagal ginjal kronis.

Tabel 3.1. Crosstab jenis terapi dengan gagal ginjal pada pasien.

\begin{tabular}{|l|l|l|l|}
\hline & $\begin{array}{l}\text { Mono- } \\
\text { terapi }\end{array}$ & $\begin{array}{l}\text { Kom- } \\
\text { binasi }\end{array}$ & total \\
\hline Tidak & $\begin{array}{l}23 \\
\text { Gagal } \\
(29,1 \%)\end{array}$ & $\begin{array}{l}13 \\
(16,5 \%)\end{array}$ & 36 \\
Ginjal & $(35,6 \%)$ \\
\hline $\begin{array}{l}\text { Gagal } \\
\text { ginjal }\end{array}$ & $\begin{array}{l}11 \\
(13,9 \%)\end{array}$ & $\begin{array}{l}(42,5 \%) \\
(54,4 \%)\end{array}$ \\
\hline Total & $\begin{array}{l}\mathbf{4 5} \\
(\mathbf{5 7 \%})\end{array}$ & $\begin{array}{l}\mathbf{3 4} \\
\mathbf{( 4 3 \% )}\end{array}$ & $\mathbf{7 9}(\mathbf{1 0 0 \% )})$ \\
\hline
\end{tabular}

Hasil Uji Chi Kuadrat $\left(\mathrm{X}^{2}\right)$ diperoleh nilai signifikan $0,001 \quad(p<0,05)$ dan CI 95\% 1.106-1.303, berarti terdapat hubungan bermakna antara jenis terapi hipertensi dengan kejadian gagal ginjal pada RSUD DR. R. Soedjono Selong. Odds Ratio (OR) di dapatkan sebesar 5.147. (CI 95\% : 1.960-13.513) menunjukkan terdapat hubungan yang bermakna antara jenis terapi hipertensi dengan kejadian gagal ginjal.

Hal ini sesuai dengan pemaparan dari penelitian Ratnasari, dkk (2013) yaitu terdapat hubungan yang bermakna antara jumlah pemberian obat hipertensi dengan kendali tekanan darah pada pasien hipertendi di polklinik ginjal dan hipertensi IPD-FKUI. Secara global, berdasarkan hal terapi hipertensi hanya 70.9\% penderita hipertensi yang menjalani terapi dan dari jumlah tersebut kurang dari $50 \%$ pasien yang tekanan darahnya tidak dapat di kontrol dengan baik. Berdasrkan penelitian Ratnasari dkk (2013) didapatkan bahwa $24 \%$ pasien dengan terapi kombinasi pada pasien hipertensi tidak terkendali dapat terjadi penuunan tekanan darah yang bermakna.

Referensi lain yang mendukung penelitian kami adalah dari Untari dkk (2014) yang menyebutkan bahwa terdapat pengaruh yang bermakna dalam penurunan tekanan darah pada pasien hemodialisa. Sebanyak $33.33 \%$ mengalami penurunan tekanan darah dengan kombinasi 2 regimen antihipertensi. Setelah di berikan ko0mbinasi 3 obat hipertensi di dapatkan $87,5 \%$ pasien mengalami penurunan tekanan darah yang bermakna.

Berdasarkan referensi tersebut penting di ingat bahwa kontrol tekanan darah yang adekuat menggunakan kombinasi terapi obat hipertensi akan mampu mencegah terjadinya gagal ginjal kronis ataupun end-stage renal disease.

Pada suatu penelitian oleh SHEP (Systolic Hypertension in Elderly 
Program) dan Systolic hypertension in euro menunjukkan meskipun kepatuhan pasien usia lanjut alam meminum obat meningkat, namun hanya $30 \%$ yang mampu menjaga tekanan darahnya dalam keadaan normal dengan menggunakan obat monoterapi. Sedangkan jika dilakukan pemberian obat hipertensi dengan terapi kombinasi didapatkan $80 \%$ responden berhasil menjaga tekanan darahnya dalam rentang normal. (McPhee, et al 2017).

\section{KESIMPULAN}

Pada penelitian ini melibatkan 79 subjek pria sebanyak 35 orang $(44,3 \%)$ dan wanita 44 orang $(55,7 \%)$. Dari ke 79 subjek tersebut diketahui Sebanyak 34 $(43,03 \%)$ orang mendapatkan monoterapi, dan 45 (56,96\%) orang lainnya menerima terapi kombinasi.

Berdasarkan penelitian yang telah kami lakukan untuk menentukan hubungan antara jenis terapi hipertensi dan angka kejadian gagal ginjal di RSUD DR. R. Soedjono selong di dapatkan bahwa terdapat hubungan bermakna dengan Relative risk 2,9x pada monterapi untuk terjadinya gagal ginjal (p 0,001).

Terapi hipertensi yang adekuat di perlukan untuk mencegah terjadinya komplikasi pada pasien. Namun tidak dapat di pungkiri selain pemberian obat anti-hipertensi yang adekuat, kepatuhan (compliance) pasien merupakan hal yang terpenting dalam usaha mengendalikan tekanan darah agar mtetap berada dalam kisaran normalnya.

\section{DAFTAR PUSTAKA}

David DS. Compliance with hypertensive therapy. Hypertension 2006.

Dorland, Newman W., 2012, Kamus Saku Kedokteran Dorland Edisi 28, EGC: Jakarta.

Hidayati T., Kushadiwijaya H \& Suhardi., 2008, Hubungan Antara hipertensi,Merokok Dan Minuman Suplemen Energi Dan Penyakit Ginjal Kronis,

Kementerian Kesehatan Republik Indonesia, 2013, Riset Kesehatan Dasar, Badan Penelitian dan Pengembangan Kesehatan Kementerian Kesehatan RI: Jakarta.

Mansjoer, Arief., Triyanti, Kuspuji., Savitri Rakhimi., Wardhani, Wahyu Ika \& Setiowulan, Wiwiek., 2004. Kapita Selekta Kedokteran. EGC: Jakarta.

Morgado, Elsa \& Neves, Pedro Leao., 2012, Hypertension and Chronic Kidney Disease: Cause and Consequence-Therapeutic

Consideration. Nephrology Departement, Hospital Of Faro: Portugal.

National Kidney Foundation, 2013, The National Kidney Foundation: Kidney Disease About Chronic Kidney Disease.

Price, Sylvia A \& Wilson, Lorraine M., 2013, Patofisiologi Konsep Klinis Proses-Proses Penyakit, Vol 2 Edisi 4, EGC: Jakarta.

Ratnasari F. Et al. 2013. Hubungan Jumlah Kombinasi Obat AntiHipertensi Terhadap Kendali Tekanan Darah Pada Pasien Poliklinik Ginjal Dan Hipertensi 
IPD-UI. Fkultas kedokteran UI. Jakarta.

Sastroasmoro, Sudigdo., 2011, DasarDasar Metodologi Penelitian Klinis Edisi Ke-4, Jakarta : Sagung Seto.

Sudoyo, Aru W., Setiyohadi, Bambang., Alwi, Idrus., K, Marcellus Simadibrata \& Setiati, Siti., 2009, Buku Ajar Ilmu Penyakit Dalam Edisi Ke-5 Jilid $\mathrm{Ke}$-2, Interna Publishing: Jakarta.

Untari M. K. Et al 2014. Perbandingan efek terpi kombinasi 2 obat dengan 3 obat antihipertensi pada pasien hemodialisa. Jurnal manajeman dan pelayanan farmasi. Jakarta.

USRD (United States Renal Data System), 2013, USRDS Annual Data Report. 